\title{
EL CONTROL DE CONVENCIONALIDAD: ¿DECLINACIÓN DE LA JUSTICIA CONSTITUCIONAL O AUTÓNOMO SISTEMA DE "JUSTICIA CONVENCIONAL TRANSNACIONAL"?1
}

\author{
CONVENTIONALITY CONTROL: CONSTITUTIONAL JUSTICE DECLINATION OR \\ AUTONOMOUS SYSTEM OF “TRANSNATIONAL CONVENTIONAL JUSTICE”?
}

Por SILVLA BAGNI ${ }^{(*)}$

\begin{abstract}
RESUMEN: la autora analiza la doctrina del control de convencionalidad en sentido amplio, como aplicada no sólo por la Corte interamericana, sino también por otros sistemas jurídicos supranacionales, con el objetivo de entender si su naturaleza y funciones justifican su inclusión en el ámbito de estudio del Derecho constitucional, específicamente como una declinación de la justicia constitucional; o si, en cambio, es necesario elaborar un nuevo marco teórico para fundamentar tal doctrina. La autora apoya la tesis que control de convencionalidad y justicia constitucional tienen fundamentos teóricos distintos, y que se debería hablar de una autónoma disciplina de la "justicia convencional transnacional". Para fundamentar su proposición, la autora primero analiza la recepción del Derecho internacional por parte de los ordenamientos nacionales; luego, estudia la teoría y la praxis del control de convencionalidad, enfocándose en la crítica de los presupuestos de comparabilidad y en al análisis del funcionamiento de los sistemas IDH, EDU y UE, que, cada uno con sus especificidades, aplican el control de convencionalidad.
\end{abstract}

PALABRAS CLAVES: control de convencionalidad - justicia constitucional - ciencia jurídica - protección de derechos humanos - desaplicación difusa

\begin{abstract}
: the author analyzes the doctrine of conventionality control in a broad sense, which is not only as applied by the Inter-American Court of Human Rights, but also by other supranational legal systems. The article's aim entail in understand if the nature of the conventionality control is the same as that of constitutional justice; or instead, if it's necessary to create a new theoretical framework for this human rights protection's instruments. The authoress supports the idea that conventionality control and constitutional justice are based on very different principles and ratio, and that it would be methodologically more appropriate to consider the "transnational conventional justice" as an autonomous discipline. In order to support her thesis, firstly the author studies the incorporation of international Law by national legal systems; then, she scans conventionally control's theory and praxis, chiefly criticizing the comparability assumptions, and then describing in details the functioning of the three supranational systems that apply the conventionality control (UE, IDH and EDU).
\end{abstract}

KEY WORDS: conventionality control - constitutional justice - legal science - human rights protection diffuse inapplicability

${ }^{1}$ Artículo recibido el 10 de julio de 2020 y aprobado para su publicación el 20 de julio de 2020.

(*) Silvia Bagni es Doctora en Derecho constitucional e investigadora en Derecho público comparado por la Universidad de Bolonia. Ha sido miembro del Virtual Dialogue 2016 of the General Assembly on Harmony with Nature, Panel 1. Earth-centered Law, Naciones Unidas, y es miembro del Consejo del Cirsfid (Centro Interdipartimentale di Ricerca in Storia del Diritto, Filosofia e Sociologia del Diritto e Informatica Giuridica dell'Università degli Studi di Bologna «Guido Fassò - Augusto Gaudenzi»), miembro fundador del Centro studi sull'America latina del Departamento de Ciencias políticas y sociales de la Universidad de Bolonia, miembro de la sección italiana del Instituto iberoamericano de Derecho constitucional. Miembro de la redacción de Bolonia de la Revista general de Derecho público comparado, miembro de la Associazione di Diritto Pubblico Comparato e Europeo y de la redacción de Bolonia de la misma Revista. Socio SIRD (Società italiana per la ricerca nel Diritto comparato). silvia.bagni@,unibo.it. El presente articulo ha sido publicado en Revista Temas de Derecho Constitucional (Corte constitucional de Colombia, Bogotá), n. ${ }^{\circ}$ 1, 2019, pp. 287-314, ISSN 2711-1105. 


\section{(c) $(1)(2)(9$}

Artículo publicado bajo Licencia Creative Commons Atribución-No Comercial-Sin Derivar. (C) Universidad Católica de Córdoba

DOI http://dx.doi.org/10.22529/rdm.2020(3)02 


\section{Problemas teóricos en enmarcar el estudio del control de convencionalidad dentro la materia de la justicia constitucional}

En doctrina, las expresiones "internacionalización del Derecho constitucional" y “constitucionalización del Derecho internacional" (Ferrer Mac-Gregor, 2011; Chang, Yeh, 2012: 1165-1184; se usa también la expresión Ius Constitutionale Commune: A. Von Bogdandy, 2015: 27) son, hoy en día, inflacionarias. La primera representa la tendencia del Derecho constitucional hacia la recepción del Derecho internacional en el bloque constitucionalidad. La segunda, la reproducción, a nivel supranacional, de mecanismos jurisdiccionales típicos del Derecho constitucional, orientados a la garantía de la supremacía de los tratados (en particular, sobre derechos humanos) frente a las otras fuentes del Derecho. Estos fenómenos pueden producir mecanismos de prejudicialidad, como acontece con el Tribunal de Justicia de la Unión europea (TJUE) ${ }^{3}$, o formas de control de convencionalidad en sentido amplio, es decir de no aplicación del Derecho interno incompatible con la norma supranacional, como pasa en el Derecho de la UE y en los sistemas regionales europeo (EDU) e interamericano (IDH) de tutela de los derechos humanos.

Hablar de control de convencionalidad en América latina, siendo una investigadora europea, tiene sus riesgos. La bibliografía hoy en día es inmensa y no pretendo manejarla toda. El objetivo de este trabajo es más modesto y propone abordar el tema desde una perspectiva metodológica que considero un tanto nueva en el panorama académico latinoamericano; es decir, reflexionar sobre la naturaleza del control de convencionalidad como objeto de estudio del Derecho constitucional, un poco como lo hicieron en su tiempo Alcalá Zamora y Fix-Zamudio, al interrogarse sobre la naturaleza del Derecho procesal constitucional.

Voy a reflexionar sobre la naturaleza del control de convencionalidad en sentido amplio, para verificar si su ratio y las funciones que cumple pueden incorporarse en concepto de justicia constitucional o si, en cambio y como apoyamos en este artículo, deben considerarse como un sistema de garantías autónomo, que necesita de un especifico marco teórico de legitimación.

Fix-Zamudio, cuando define el «Derecho procesal constitucional» individualiza tres grandes sectores: 1) la jurisdicción constitucional de la libertad;2) la jurisdicción constitucional orgánica; 3 ) la jurisdicción constitucional transnacional (Fix-Zamudio, 1999: 105). Esta última tiene como objeto el estudio de las relaciones y de los conflictos entre la aplicación de normas constitucionales y transnacionales, cruzándose con la jurisdicción constitucional de la libertad por causa de la incorporación del Derecho internacional de los derechos humanos en la mayoría de las cartas constitucionales nacionales. Esto significa que el control de convencionalidad está incluido dentro del Derecho procesal constitucional.

En Italia, Pizzorusso dedica una sección de la voz Giustizia costituzionale (diritto comparato) en la famosa Enciclopedia del diritto a Casi di giustizia costituzionale internazionale e comunitaria, afirmando que hay que mirar a las «prospettive di applicazione degli istituti di giustizia costituzionale a livello internazionale o sovranazionale»; pero también advirtiendo que «Di giustizia costituzionale internazionale può parlarsi soltanto in un significato limitato e particolare, in quanto l'ordinamento giuridico della comunità internazionale non presenta tutti i presupposti che occorrerebbero perché in esso possa instaurarsi un sistema di controllo di costituzionalità di atti normativi analogo a quelli che operano con riferimento agli ordinamenti statali» (Pizzorusso, 2007: 671 y 707). Los manuales de justicia constitucional más recientes siguen tratando muy poco o para nada el tema, con un enfoque principalmente descriptivo o concentrado en el "diálogo" entre cortes.

\footnotetext{
${ }^{3}$ El mecanismo de la prejudicialidad existe también en otros sistemas de integración regional que prevén una Corte supranacional para la resolución de conflictos, como el SICA (Sistema de integración centroamericana). Sin embargo, la asimilación entre este sistema y el de la UE es engañoso: véase Carducci, 2012.
}

\begin{tabular}{llll}
\hline REVISTA DERECHO DE LAS MINORIAS & VOLUMEN 3 & 2020 & Page 22
\end{tabular} 
En Francia, en la segunda edición del famoso libro Les cours constitutionnelles, sus autores afirman que «il n'est plus possible d'appréhender l'étude des cours constitutionnelles abstraction faite, non du droit européen (ceci a toujours relevé de l'évidence), mais de leurs rapports avec la Cour de justice de l'Union européenne [...]», aún si enseguida se reconoce que en derecho público ha nacido una nueva disciplina sobre el tema («rapport de systèmes») (Favoreu, Mastor, 2016: 33).

Finalmente, en España, los constitucionalistas tienen un enfoque mucho más casuístico del tema de la justicia constitucional, así que se profundiza en el marco del estudio de las garantías de los derechos fundamentales o del rol del Tribunal Constitucional (TC) en la forma de Estado y de gobierno (González-Trevijano Sánchez, 2000). Los problemas relativos a la armonización de la jurisdicción constitucional con la supranacional son analizados autónomamente, fuera del marco de la justicia constitucional, según la vía sugerida por el mismo TC en su jurisprudencia donde afirma su extrañeza hacia el control de convencionalidad ${ }^{4}$.

Del breve análisis realizado, se desprende que las relaciones que la doctrina ha subrayado entre sistemas de justicia constitucional y convencional nacen de compartir un mismo ámbito de aplicación, los derechos humanos y de la incorporación del derecho internacional dentro de las constituciones. Sin embargo, sin incorporación, los dos sistemas quedarían distintos y separados: la violación de un tratado por parte del Estado produciría a su cargo sólo una obligación de cumplimiento bajo del Derecho internacional. Por esta razón, a continuación voy a comparar los sistemas de recepción del Derecho internacional en cada Estado, limitadamente a Europa y América Latina, en cuanto únicos sistemas regionales donde se practica el control de convencionalidad en sentido amplio ( $($ II); luego, analizaré la tendencia europea hacia la incorporación del control de convencionalidad dentro del sistema de justicia constitucional interno y sus excepciones( $($ III) y estudiaré la opuesta tendencia en América Latina y en el sistema del derecho de la UE, proponiendo algunas críticas $(§ I V)$; y, finalmente, esbozaré unas conclusiones $(\mathbb{V}$ ).

\section{La recepción del Derecho internacional dentro de los ordenamientos nacionales}

En Europa, la mayoría de las constituciones reconocen rango supra-legislativo (sobre todo en los Estados del Este: Salvino, 2017: 193) al Derecho internacional, en particular a los derechos humanos, o tal vez valor constitucional, come en Austria y Holanda. Hay un grupo de países que formalmente atribuye a los tratados el mismo valor de la ley (Bélgica, Dinamarca, Finlandia, Alemania, Irlanda, Letonia, Lituania, Reino Unido ${ }^{5}$ ). Sin embargo, en estos ordenamientos ha sido la jurisprudencia de las altas cortes la encargada de reconocer la supremacía de los tratados sobre la ley. Esto significa que, bajo la teoría de las fuentes, la CEDU está incorporada dentro del bloque de constitucionalidad, como norma interpuesta o parámetro directo del control de constitucionalidad de la ley.

En cuanto a la participación a la UE, casi todos los Estados han incluido -en sus constituciones- cláusulas que definen su pertenencia a la UE o el procedimiento previsto para el acceso y la permanencia en el sistema. En casos particulares (Dinamarca, Estonia, Italia, Luxemburgo, Holanda, Polonia, Eslovenia, España), la adhesión ha sido aceptada bajo normas constitucionales generales, que admiten la transferencia de poderes o funciones o la renuncia parcial aparte de la soberanía a favor de organizaciones internacionales para la defensa de la paz y la tutela de los derechos humanos (Salvino, 2017: 205; Di Gregorio, 2004).

${ }^{4}$ Hay excepciones: cfr. Pérez Tremps, 2016.

${ }^{5}$ En España, el art. 96, c. 1, de la CE, afirma que forman parte del ordenamiento jurídico; el art. 95 prevé el control de constitucionalidad previo eventual; el art. 10, c. 2 consigna que los derechos constitucionales deben ser interpretados de manera conforme a los tratados sobre derechos humanos ratificados por el Estado. 
Entre los Estados que pertenecen al sistema interamericano(Sagüés, s.f.: 392; Rolla, 2010),se encuentran tres distintas soluciones ${ }^{6}$ : la más difusa reconoce a los tratados rango infraconstitucional, es decir que los tratados son subordinados a la Constitución, pero superiores a las leyes. La segunda hipótesis atribuye a los tratados sobre derechos humanos rango constitucional, así que se consideran incluidos en el bloque de constitucionalidad. Finalmente, en algunos países, la constitución afirma que las normas que reconocen derechos humanos se interpretan en conformidad con los tratados internacionales o, en alternativa, los tratados sobre derechos humanos prevalecen si más favorables, así que de hecho tienen valor supra-constitucional ${ }^{7}$.

\begin{tabular}{|c|c|c|}
\hline \multicolumn{3}{|c|}{ Recepción del Derecho internacional de los derechos humanos en Iberoamérica } \\
\hline $\begin{array}{c}\text { Rango } \\
\text { supra-constitucional }\end{array}$ & Rango constitucional & $\begin{array}{c}\text { Rango } \\
\text { infra-constitucional }\end{array}$ \\
\hline 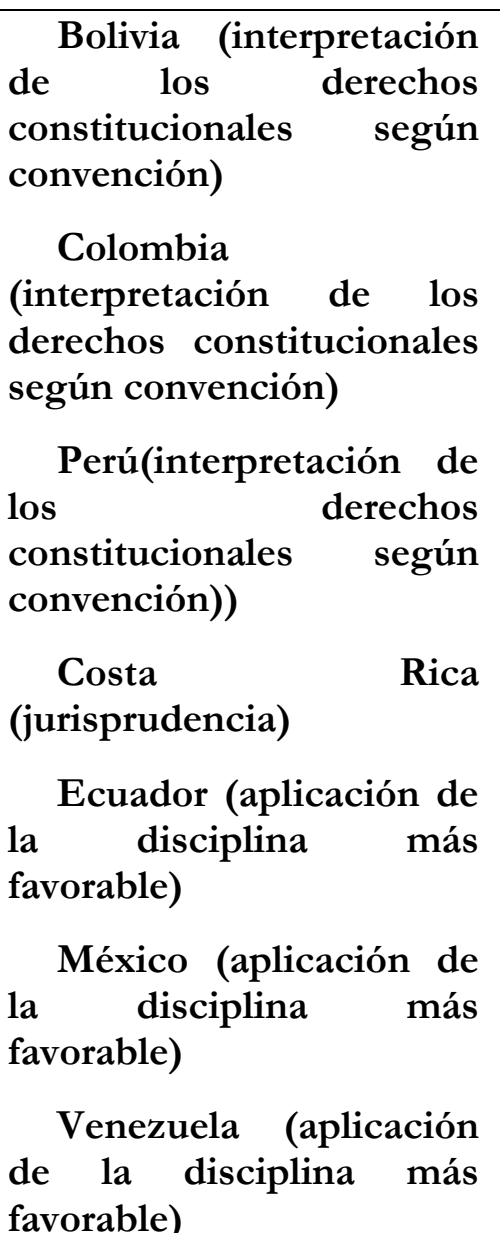 & $\begin{array}{l}\text { Argentina } \\
\text { Brasil } \\
\text { Colombia } \\
\text { (jurisprudencia) } \\
\text { México } \\
\text { República dominicana } \\
\text { Venezuela }\end{array}$ & $\begin{array}{l}\text { Bolivia } \\
\text { Brasil (jurisprudencia) } \\
\text { Chile } \\
\text { Costa Rica } \\
\text { Ecuador } \\
\text { E1 Salvador } \\
\text { Guatemala } \\
\text { Haití } \\
\text { Honduras } \\
\text { Nicaragua } \\
\text { Panamá } \\
\text { Paraguay } \\
\text { Surinam } \\
\text { Uruguay } \\
\text { (jurisprudencia) }\end{array}$ \\
\hline
\end{tabular}

Veamos en detalle las primeras dos soluciones.

\footnotetext{
${ }^{6}$ En los países no incluidos en el esquema no existen normas constitucionales dedicadas a la jerarquía de las fuentes o al rango de los tratados.

${ }^{7}$ La palabra“(jurisprudencia)" significa que la clasificación es consecuencia de la interpretación de la Corte constitucional o suprema del país.
} 
El art. 75, n. 22 Const. Argentina, describiendo las competencias del Congreso, afirma que la CIDH y los otros tratados indicados «en las condiciones de su vigencia, tienen jerarquía constitucional, no derogan artículo alguno de la primera parte de esta Constitución y deben entenderse complementarios de los derechos y garantías por ella reconocidos. Sólo podrán ser denunciados, en su caso, por el Poder Ejecutivo Nacional, previa aprobación de las dos terceras partes de la totalidad de los miembros de cada Cámara». La compatibilidad de la Convención con el núcleo duro de la Constitución, es decir con la primera parte de la carta magna, viene expresamente reconocida, así que los derechos son entre sí complementarios.

La Constitución boliviana es explícita cuando describe, en el art. 410, la jerarquía de las fuentes: «II. La Constitución es la norma suprema del ordenamiento jurídico boliviano y goza de primacía frente a cualquier otra disposición normativa. El bloque de constitucionalidad está integrado por los Tratados y Convenios internacionales en materia de Derechos Humanos y las normas de Derecho Comunitario, ratificados por el país. La aplicación de las normas jurídicas se regirá por la siguiente jerarquía, de acuerdo a las competencias de las entidades territoriales: 1. Constitución Política del Estado. 2. Los tratados internacionales. 3. Las leyes nacionales, los estatutos autonómicos, las cartas orgánicas y el resto de legislación departamental, municipal e indígena. 4. Los decretos, reglamentos y demás resoluciones emanadas de los órganos ejecutivos

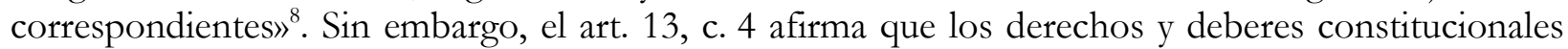
se interpretan conformemente a los tratados internacionales sobre derechos humanos ratificados por el Estado, así que la constitución viviente está sometida al derecho internacional. Lo mismo se encuentra en Colombia (art. 93, reforma constitucional 2001) y en la disposición final y transitoria cuarta de la Constitución peruana.

El art. 78, c. 3 Const. Brasil equipara los tratados aprobados en dos votaciones consecutivas por los $3 / 5$ de cada Cámara a la revisión constitucional ${ }^{9}$.

En Ecuador, el art. 425 define el orden de las fuentes del derecho: «El orden jerárquico de aplicación de las normas será el siguiente: La Constitución; los tratados y convenios internacionales; las leyes orgánicas; las leyes ordinarias; las normas regionales y las ordenanzas distritales; los decretos y reglamentos; las ordenanzas; los acuerdos y las resoluciones; y los demás actos y decisiones de los poderes públicos». Sin embargo, el art. 424 precisa que la Constitución y los tratados internacionales de derechos humanos de contenido más favorable prevalecen sobre cualquiera norma o acto público, así reconociéndoles rango supraconstitucional. Lo mismo está previsto por el art. 23 Const. Venezuela.

En México, el art. 1, c. 2 impone de interpretar todas las normas en materia de derechos humanos conformemente a la Constitución y a los tratados internacionales, que se encuentran por consecuencia al mismo nivel que la Constitución, pero aplicando un criterio de prevalencia hacia la fuente que garantiza una tutela más amplia. En la República dominicana el art. 74, n. 3) afirma que «Los tratados, pactos y convenciones relativos a derechos humanos, suscritos y ratificados por el Estado dominicano, tienen jerarquía constitucional y son de aplicación directa e inmediata por los tribunales y demás órganos del Estado», estableciendo la equi-ordenación entre las fuentes, en cambio que la jerarquía.

\footnotetext{
${ }^{8}$ Conformemente, el art. 4 de la Ley del Tribunal Constitucional Plurinacional n. 27/2010, y el Código de Derecho procesal constitucional, que afirman que los tratados se aplican en cuanto compatibles con la Constitución, tanto que está previsto el control de constitucionalidad previo no obligatorio.

${ }^{9}$ Con excepción del caso previsto, el STF ha establecido que los tratados aprobados antes de la revisión constitucional (EC 45/2004) tienen valor infra-constitucional, es decir inferior a la constitución, pero superior a la ley (RE n. 349.703-1 del 2008, fallo contestado, aprobado con un solo voto de diferencia). Defiende el valor constitucional de todos los tratados sobre derechos humanos, De Oliveira Mazzuoli, 2016.
} 


\section{El Derecho internacional como parámetro en el juicio de constitucionalidad dentro del sistema EDU: tendencia mayoritaria y excepciones}

Bajo la teoría constitucional de la supremacía de la Constitución y de la jerarquía de las fuentes del Derecho, la constitucionalización del Derecho internacional implicaría su inclusión en el parámetro del juicio de constitucionalidad de las normas, según el modelo de justicia constitucional de cada país y la aplicación de la ponderación en caso de conflictos entre normas del mismo nivel.

Esta hipótesis es correcta por lo que tiene a que ver con el sistema EDU (aún con algunos casos particulares); en cambio, es falsa, si aplicada al derecho de la UE, como en la mayoría de los países latinoamericanos del sistema IDH.

En Europa, la desaplicación del Derecho interno incompatible con la CEDU por parte de los jueces ordinarios es todavía una excepción. In primis, se encuentra en países donde no existe un sistema jurisdiccional de control de constitucionalidad. Por ejemplo, en Holanda, las cortes ordinarias realizan el control de convencionalidad difuso ex art. 94 Const $^{10}$. En el Reino Unido, la Human Rights Act de 1998 ha introducido una forma de control difuso de convencionalidad, que sin embargo no produce como consecuencia la directa desaplicación de la norma interna incompatible en el caso concreto, sino, ex art. $4^{11}$, la declaración de incompatibilidad, que deja al Parlamento la tarea de solucionar el conflicto por vía legislativa, cuando existen «compelling interests» (art. 10, c. 2). La declaración no afecta ni la eficacia ni la validez del acto, y tampoco produce efectos vinculantes para las partes. Bélgica es en parte comparable con el caso holandés, porque el "control de convencionalidad" fue introducido por vía jurisprudencial ${ }^{12}$, cuando todavía el ordenamiento no había introducido el modelo jurisdiccional de control de las leyes, así que después su introducción, los jueces se mantuvieron el poder de desaplicar el derecho interno contrastante con una norma internacional self-executing.

Un caso verdaderamente interesante se encuentra en Francia, donde la hibridación del sistema de control de constitucionalidad y la previsión constitucional de la supremacía de los tratados sobre la ley (art. 55 const.) ha llevado el Conseil Constitutionnel a legitimar el control de convencionalidad difuso, que sigue siendo defendido aún después de la introducción de la question prioritaire $^{13}$ (Dutheillet De Lamothe, 2010): con la sentencia n. ${ }^{\circ} 74-54$, de 15 de enero de 1975, Interruption volontaire de grossesse (IVG), el Conseil se declaró no competente en la actuación del control de convencionalidad, y lo mismo en caso de controla posteriori, con la dec. N. 2010-605, de 12 de mayo 2010, Jeux de hasard, reconociendo que esta tarea pertenece a los jueces ordinarios. La Ley orgánica ha especificado que el juez a quo debe otorgar precedencia al control de constitucionalidad sobre al juicio de convencionalidad, al parecer este es un reconocimiento de la supremacía de la Constitución sobre los tratados. La situación francesa puede parecer un poco absurda, considerando que los jueces ordinarios tienen el poder de realizar el control de convencionalidad difuso, pero en caso de incompatibilidad de una ley con la Constitución no están legitimados a desaplicarla, pues deben dirigir una QPC al Conseil. En doctrina, se asevera que

\footnotetext{
10 «Statutory regulations in force within the Kingdom shall not be applicable if such application is in conflict with provisions of treaties or of resolutions by international institutions that are binding on all persons».

11 «If the court is satisfied-

(a)that the provision is incompatible with a Convention right, and

(b)that (disregarding any possibility of revocation) the primary legislation concerned prevents removal of the incompatibility, it may make a declaration of that incompatibility».

12 Caso Franco Suisse Le Ski, decidido por la Corte Suprema de Casación el 27 de mayo de 1971.

${ }_{13}$ Décision $n^{\circ} 74-54$ DC du 15 janvier 1975 recueil p. 19, del Conseil constitutionnel, que rechaza la propia competencia al control de convencionalidad de los tratados; Décision n 86-216 DC du 3 septembre 1986, recueil p. 135 e $n^{\circ} 89-268$ DC du 29 décembre 1989, recueil p. 110, que invitan las cortes ordinarias a asumir esta tarea; affaire des cafés Jacques Vabre della Cour de Cassation, en 1975 yaffaire Nicolo del Conseil d'Etat nel 1989, donde las cortes aplican la jurisprudencia constitucional; Décision $n^{\circ} 2010-605$ DC du 12 mai 2010, recueil, p. 78, con la cual el Conseil confirma su incompetencia al control de los tratados.
}

\begin{tabular}{llll}
\hline REVISTA DERECHO DE LAS MINORIAS & VOLUMEN 3 & 2020 & Page 26
\end{tabular} 
«'appréciation comparée du contrôle de conventionnalité et du contrôle a posteriori de constitutionnalité par la QPC montre que les contrôles n'ont ni le même objet ni le même but, même si la disposition législative contestée est identique» (Drago, 2016: 504).

En España, el tema del control difuso de convencionalidad divide la doctrina (Jimena Quesada' 2013; Jimena Quesada, 2018: 31; Canosa Usera ${ }^{20} 15$ : 237 ss.) y produce incertidumbre entre las cortes. De un lado, «la Corte Constitucional española, en materia de control de convencionalidad, ni hace ni deja hacer» (Jimena Quesada ${ }^{2018)}$; del otro, algunos jueces ya han realizado un control de convencionalidad aclaraNdo que el art. $96 \mathrm{CE}$ no determina la incorporación de los tratados dentro del bloque de constitucionalidad, sino una relación de "competencia" entre fuentes, y, como consecuencia, el deber del juez de elegir cuál es la norma aplicable al caso concreto, sin perjuicio de la validez de la norma interna (f.j. 6) ${ }^{14}$. En cuanto al art. 10.2 CE, el Tribunal ha afirmado que «no es canon autónomo de constitucionalidad, sino que se limita a definir una pauta hermenéutica obligatoria destinada al Tribunal Constitucional y al resto de intérpretes y aplicadores del título I de la Constitución» (f.j. 5). Esto significa que los tratados no albergan valor constitucional y no pueden ser utilizados como normas interpuestas en el control de constitucionalidad.

Fuera de los casos particulares analizados, en Europa la garantía de los derechos convencionales se realiza tramite el sistema de justicia constitucional propio de cada ordenamiento: donde el modelo es concentrado, tramite recurso directo o excepción de inconstitucionalidad a la Corte constitucional, que declara la norma interna inconstitucional por violación de la CEDU, si no hay un derecho constitucional directamente aplicable (Pollicino, 2010: 448; Salvino, 2017: 144) ${ }^{15}$; donde el modelo de justicia constitucional es difuso o mixto, tramite la desaplicación caso por caso ${ }^{16}$.

En América Latina, la situación es más complicada por dos razones: de un lado, ya hemos visto que algunas constituciones reconocen a la CIDH y a los tratados sobre derechos humanos rango supra-constitucional; de otro lado, la Corte IDH ha desarrollado la doctrina del control de convencionalidad como directa desaplicación del Derecho interno incompatible por parte de cualquier órgano estatal, obligado a implementar el Convenio por arriba del derecho interno, aun de nivel constitucional.

La teoría de la integración del control de convencionalidad dentro de la justicia constitucional se podría defender respecto de los países que en América latina aplican un modelo difuso de constitucionalidad, como Argentina ${ }^{17}$ y algunos países del Caribe ${ }^{18}$. De hecho, aún en estos casos, el sistema implementado por la Corte IDH sigue siendo incompatible con la justicia constitucional, en razón de la pretendida completa subordinación del ordenamiento nacional a la jurisprudencia creativa, general y vinculante de la $\operatorname{Corte}^{19}$, que se propone como órgano de clausura de un sistema supranacional, por arriba de la jurisprudencia de las más altas cortes del poder judicial

\footnotetext{
14 «En suma, el análisis de convencionalidad que tiene cabida en nuestro ordenamiento constitucional no es un juicio de validez de la norma interna o de constitucionalidad mediata de la misma, sino un mero juicio de aplicabilidad de disposiciones normativas» (f.j. 6).

${ }^{15}$ Caso emblemático es el sistema italiano. Hasta la reforma constitucional de 2001, el Derecho internacional convencional tenía el rango de la fuente que lo incorporaba en el ordenamiento jurídico, normalmente la ley. Con el nuevo art. 117, c. 2 Const. y su interpretación por parte de las sentencias gemelas de la Corte constitucional n. 348-349/2007, el Derecho internacional convencional es considerado norma interpuesta en el control de constitucionalidad.

${ }^{16} \mathrm{En}$ algunos casos, la desaplicación no está prevista ni por el ordenamiento, ni por la jurisprudencia constitucional, y su legitimidad es muy controvertida (Bulgaria, Portugal). Cfr. G. Martinico, O. Pollicino, 2012: 132.

${ }^{17}$ La Corte Suprema argentina, a partir del caso Giroldi de1995, ha afirmado que el control de convencionalidad está incluído en el control difuso de constitucionalidad.

18 Pero también en México, después de la reforma de 2011 y de la nueva jurisprudencia de la Corte Suprema.
} 
nacional (la Corte Suprema) y del órgano de garantía de la voluntad constituyente positivizada en la Constitución (la Corte constitucional o la Sala constitucional de la Corte Suprema).

\section{Teoría y praxis del control de convencionalidad en América y Europa}

Cuando el Derecho internacional tiene rango supra-constitucional, la teoría clásica de la jerarquía de las fuentes sufre problemas de coherencia interna con la idea de Constitución como "ley suprema". La justicia constitucional nace como instrumento de garantía de esta superioridad, que se fundamenta en su legitimación popular y en su naturaleza de expresión del poder constituyente de origen popular (Canosa Usera, 2015: 248). Su fundamento filosófico es el constitucionalismo liberal-democrático, que nace como teoría de la limitación del poder. En consecuencia, el objetivo primario de la justicia constitucional, al principio, no era la tutela de los derechos, sino el control del ejercicio del poder normativo, tanto en sentido vertical, entre poder constituyente y poderes constituidos, como en sentido horizontal, entre poder legislativo central y poderes legislativos de las entidades territoriales. En otro lugar, he definido esta fase como modelo "nomocrático" de justicia constitucional, en cuanto el poder normativo es el único objeto de control (Bagni, 2017).

Sólo después de las dos guerras mundiales y de la tragedia del genocidio judío, el objetivo de la justicia constitucional se centra en la tutela de los derechos humanos. Esta fase corresponde a un cambio en el pensamiento constitucional hacia el "neoconstitucionalismo", que reconoce el valor normativo y vinculante de la Constitución, en cuanto conjunto de derechos y libertades, e individualiza el poder judicial como su propio instrumento de garantía. He definido esta fase como modelo "pantocrático", porque el control constitucional jurisdiccional se extiende a lo largo de los años, al ejercicio de todos los poderes: ejecutivo, judicial, popular, electoral, de reforma constitucional. Al mismo tiempo, en el ámbito internacional se producen las primeras declaraciones universales de los derechos humanos y los iniciales convenios regionales vinculantes sobre derechos fundamentales. Los sistemas regionales se dotan de formas de garantías jurisdiccionales, para asegurar el respeto de los derechos convencionales en casos concretos. Sin embargo, al principio los individuos no pueden acudir directamente a los tribunales internacionales: la violación del tratado produce sólo responsabilidad internacional. Pero, como en la mayoría de los casos, los derechos humanos convencionales corresponden a los derechos constitucionales, su garantía se realiza a menudo a través de los sistemas de justicia constitucional internos. Cuando los individuos obtienen el acceso directo a las cortes supra-nacionales, como en el sistema EDU, la teoría constitucional de las fuentes y del control de constitucionalidad ya no es suficiente para explicar el fenómeno. Prevalece la doctrina de los derechos humanos, cuya legitimidad no deriva ni del tipo de fuente, ni de su legitimación popular (Ruggeri, 2019: 21), sino de su contenido, que se reconoce como pre-jurídico y universal (Spadaro, 2006: 1635; Ruggeri, 2007: 320). El único criterio de resolución de las antinomias es la aplicación de la fuente que asegura mejor tutela al derecho controvertido (Jimena Quesada, 2018: 34; de Figueiredo Caldas, 2013: 397; Nogueira Alcalá, 2013: 548). El "nuevo" constitucionalismo latinoamericano, tomando inspiración tanto del constitucionalismo liberal-democrático como del neoconstitucionalismo y de la teoría de los derechos humanos, intenta combinar las distintas perspectivas, que, pero, parecen incompatibles sin un esfuerzo de síntesis original e innovador (Canosa Usera, 2015: 237). La dificultad en compatibilizar los fundamentos de los dos sistemas de garantías se encuentra expresada en la jurisprudencia de las cortes constitucionales europeas sobre los contra-límites y la jurisprudencia de la Corte EDU sobre el margen de apreciación, ambas utilizadas para reconducir el sistema supranacional de tutela de los

\footnotetext{
${ }^{19}$ Según la jurisprudencia de la Corte IDH, sus fallos vinculan a todos los Estados miembros, aún sin ser partes en el juicio. La Corte lo ha reiterado en el caso Cabrera García y Montiel Flores vs. México, de 2010, p. 79, del voto razonado del juez Ferrer Mac-Gregor, 2011c.
} 
derechos humanos dentro de los límites teóricos del constitucionalismo liberal-democrático. La doctrina de los contra-límites postula la supremacía jerárquica del núcleo duro de la constitución, también sobre los tratados de derechos humanos, y reconoce las Cortes constitucionales nacionales como últimos guardianes de esta relación. El criterio interpretativo del margen de apreciación corresponde a la formalización del self restraint de una Corte supranacional que rechaza su legitimación a interpretar de manera extensiva el catalogo de los derechos establecidos en el convenio, cuando no hay plena correspondencia con las "tradiciones constitucionales comunes entre los Estados miembros", que son el producto de la jurisprudencia constitucional consolidada de cada Estado (García Roca, 2010).

Un argumento largamente utilizado para justificar la incorporación del control de convencionalidad dentro la doctrina constitucional es que en América Latina (excepto el caso mexicano), todas las constituciones que han incorporado el Derecho internacional han entrado en vigor después del $\mathrm{CIDH}$, así que la vinculación al sistema IDH es una libre elección del poder constituyente.

Cuando la Constitución reconoce a los tratados internacionales su mismo valor extiende el parámetro del control de constitucionalidad a un texto cuyo contenido ha sido establecido por órganos externos al ordenamiento, pero cuya interpretación debería quedarse en el órgano de cierre del sistema constitucional, es decir la Corte constitucional misma, vinculada a los límites formales del tratado y, eventualmente, a la interpretación de sus normas producida por su propio tribunal, cuando previsto. Estamos en la hipótesis de integración del sistema EDU dentro el sistema constitucional interno a cada Estado.

En cambio, hay un problema cuando la constitución reconoce a los tratados sobre derechos humanos rango supraconstitucional. Desde un punto de vista dogmático, ¿se puede considerar admisible ab origine una renuncia al carácter "supremo" de la constitución, a favor de una fuente externa de origen convencional? $\mathrm{O}$, dicho de otra manera, desde la perspectiva del sujeto titular del poder, ¿puede el titular del poder constituyente ceder este poder para el futuro, a favor de terceros externos, como otros Estados o organizaciones internacionales? Según la doctrina clásica, el poder constituyente no es delegable, en virtud de su directa legitimación popular. Locke lo explica con claras palabras, hablando del momento originario en el cual se establece el titular del poder normativo, definiendo el principio como «the first and fundamental natural law which is to govern even the legislative»:

\footnotetext{
«This legislative is not only the supreme power of the commonwealth, but sacred and unalterable in the hands where the community have once placed it. Nor can any edict of anybody else, in what form so ever conceived, or by what power so ever backed, have the force and obligation of a law which has not its sanction from that legislative which the public has chosen and appointed; for without this the law could not have that which is absolutely necessary to its being a law, the consent of the society, over whom nobody can have a power to make laws but by their own consent and by authority received from them $[\ldots] \gg(\text { Locke, } 1823)^{20}$.
}

\footnotetext{
${ }^{20}$ Argumentación parecida se encuentra en la motivación del caso Lissabon Urteil del Tribunal constitucional alemán, de 30 $\begin{array}{llll}\text { junio } & 2009, & S & 216\end{array}$ (https://www.bundesverfassungsgericht.de/SharedDocs/Downloads/EN/2009/06/es20090630_2bve000208en.pdf;jsessio nid=99E85A0F238BF4685EAD66312D15985E.1_cid361?__blob=publicationFile\&v=1): «The Basic Law does not grant powers to bodies acting on behalf of Germany to abandon the right to self-determination of the German people in the form of Germany's sovereignty under international law by joining a federal state. Due to the irrevocable transfer of sovereignty to a new subject of legitimation that goes with it, this step is reserved to the directly declared will of the German people alone» ( $(5228)$.
} 
En cambio, la aceptación de la doctrina de los derechos humanos implica la admisibilidad de una delegación en blanco en la definición del contenido de los derechos por parte de fuentes convencionales (Pizzolo, 2008:190; Martins, Oliveira Moreira, 2011:469). Las normas convencionales sobre derechos humanos no son simplemente normas interpuestas sino disposiciones de carácter supraconstitucional, que prevalecen jerárquicamente sobre los principios constitucionales. Este razonamiento, nunca explicitado por la Corte IDH, pero necesariamente sobreentendido en su jurisprudencia, especialmente la que impone revisiones constitucionales a los Estados miembros para adaptar el marco constitucional a las normas convencionales, no es de ninguna manera conciliable con la idea del Estado constitucional de derecho, ni con las teorías sobre poder constituyente o sobre la voluntad popular como fuente de legitimación de las constituciones democráticas (Sajó, S. Giuliano, 2017). En palabras del juez de la Sala constitucional de la Corte Suprema de Costa Rica: «El control de convencionalidad supone un revulsivo en la teoría de las fuentes del Derecho, un replanteamiento de una serie de categorías dogmáticas y el surgimiento de otras absolutamente novedosas» (Jinesta, 2012:3). Aún reconocidos académicos latinoamericanos apoyan la misma postura: «El control de constitucionalidad es un control diferente al de convencionalidad» (Nogueira Alcalá, 2013:545), que es complementario al primero (Bazán, 2011, 39; Pérez Tremps, 1992).

El juez de la Corte IDH Ferrer Mac-Gregor, en su voto razonado en el caso Cabrera García y Montiel Flores del 2010, habla de internacionalización de las categorías y de los instrumentos del derecho constitucional, al referirse a la doctrina del control de convencionalidad difuso ( $\$ \int 21$ e 22 ), y al deber de interpretación conforme a la convención, que corresponde a todos los jueces $(\mathbb{\$} 36)$. El afirma que «39. En caso de incompatibilidad absoluta, donde no exista "interpretación convencional" posible, si el juez carece de facultades para desaplicar la norma, se limitará a señalar la inconvencionalidad de la misma o, en su caso, "plantear la duda de inconvencionalidad" ante otros órganos jurisdiccionales competentes dentro del mismo sistema jurídico nacional». Bien que esta interpretación representa un esfuerzo de integración del control de convencionalidad dentro el marco de la justicia constitucional nacional, como pasa en la mayoría de los países del sistema EDU, el desarrollo de la jurisprudencia de la Corte IDH y la amplia doctrina en la materia niegan esta postura conciliatoria, a favor de la desaplicación directa del Derecho interno incompatible con el tratado con efecto inter partes (Rey Cantor, 2010: 563). Además, hay que considerar también que la Corte IDH ha vinculado los Estados al respeto de su jurisprudencia aún cuando no son partes del caso juzgado ${ }^{21}$, creando una norma no prevista por el tratado. La jurisprudencia asume eficacia erga omnes $^{22}$, transformando la Corte IDH en un verdadero "legislador constitucional" (como no recordar las palabras de la Corte Suprema estadounidense en el caso Cooper v. Aaron, 358 US 1 (1958): «the interpretation of the Fourteenth Amendment enunciated by this Court in the Brown case is the supreme law of the land») (Sagüés habla de Constitución convencionalizada: Sagüés, 2011).

Bajo la teoría constitucional, control de convencionalidad y control de constitucionalidad deberían convivir como sistemas paralelos y autónomos. En cambio, la Corte IDH ha introducido una relación de jerarquía en favor del sistema convencional, en tránsito hacia la imposición del control difuso. Este camino es comparable con lo que ha pasado con el proceso de integración comunitario, más que con el sistema EDU, con el cual usualmente el sistema IDH es, en cambio, comparado (Carducci, 2012; Dulitzky, 2015).

\footnotetext{
${ }^{21}$ Caso Cabrera García y Montiel Flores, 2010, p. 79 del voto razonado del juez Ferrer Mac-Gregor.

${ }^{22} \mathrm{La}$ Corte EDU habla de eficacia de res interpretata. Sin embargo, la Corte EDU no defiende la primacía del Derecho convencional sobre las constituciones de los Estados
} 
El formante legal y jurisprudencial han creado un sistema que llega más allá de la tutela del derecho violado en un caso concreto. La actual estructura del sistema es asimilable a una forma de “justicia convencional transnacional”, que garantiza la supremacía de la Convención sobre los ordenamientos internos y que absorbe (más que integra) los sistemas de justicia constitucional nacionales. Por estas razones, creo que el estudio de la materia necesita, como ya se ha realizado respecto al sistema de la UE, de la elaboración de una dogmática nueva y parcialmente autónoma respecto del Derecho constitucional e internacional, que no sólo pueda definir criterios de prevalencia, sino que sea capaz de crear una nueva teoría de las fuentes, sobre una base político-filosófica común.

Me parece que la doctrina latinoamericana justifica el control de convencionalidad sobre la base del principio pacta sunt servanda (Ferrer Mac-Gregor ${ }^{2015)}$, pero sin explicar porque el respeto de este principio conlleva automáticamente la desaplicación difusa del Derecho interno incompatible con el tratado, existiendo, en principio, otras soluciones posibles. De hecho, la doctrina cae en la misma critica ya adelantada al respecto sobre la motivación del juez Marshall en Marbury v. Madison (Zagrebelsky, Marcenò, 2012: 35).

En Europa, la doctrina alemana propuso de enmarcar el sistema europeo dentro de la idea del constitucionalismo multinivel (Pernice, s.f.). Sin embargo, la utilización del léxico de la teoría constitucional (Pernice, 1999: 707), en mi opinión, sigue produciendo malentendidos en la construcción teórica, alimentando la confusión sobre todo en el ámbito de la teoría de las fuentes y de los instrumentos de garantía, en cuanto el paradigma no substituye, sino integra la teoría constitucional, que necesita los conceptos tradicionales de Estado y Constitución (Della Cananea, 2010; Walker, 2009). Crea menos problemas la expresión "tutela multinivel de los derechos", porque no tiene alcance prescriptivo, sino descriptivo, en cuanto no alude a ningún principio-guía para la integración de los distintos niveles o la resolución de eventuales conflictos (Tega, 2012: 44).

Después del tentativo de esbozar la teoría del control de convencionalidad y de argumentar su crítica, a continuación, voy a describir el camino seguido por la Corte IDH, el sistema del derecho de la UE y los desarrollos en el sistema EDU, para construir un modelo autónomo de "justicia convencional transnacional".

\section{IV.1. El sistema IDH frente a los ordenamientos nacionales}

El objetivo declarado del Pacto de San José es crear un sistema subsidiario de tutela de los derechos respecto a los ordenamientos nacionales. De hecho, en el preámbulo se lee que la derivación de los derechos de la naturaleza misma de la persona humana, y no de la voluntad constituyente de las Naciones, justifica «una protección internacional, de naturaleza convencional coadyuvante o complementaria de la que ofrece el derecho interno de los Estados americanos» (cursivo mío).

Aunque el sistema interamericano pueda parecer mucho al europeo, hay sin embargo características fundamentales que ponen una distancia entre los dos, además reforzada por la jurisprudencia de la Corte. In primis, la norma de adecuación del art. 2, que no existe en el sistema europeo (Ragone, 2017: 282): «Artículo 2. Deber de Adoptar Disposiciones de Derecho Interno. Si el ejercicio de los derechos y libertades mencionados en el artículo 1 no estuviere ya garantizado por disposiciones legislativas o de otro carácter, los Estados Partes se comprometen a adoptar, con arreglo a sus procedimientos constitucionales y a las disposiciones de esta Convención, las medidas legislativas o de otro carácter que fueren necesarias para hacer efectivos tales derechos y libertades». 
Es una obligación positiva de compatibilizar el ordenamiento interno a la CIDH, adoptando, si necesario, reformas legislativas o actos de otra naturaleza. El alcance de la expresión «o de otro carácter» ha sido aclarado por la Corte IDH, que ha incluso hasta reformas constitucionales.

El art. 54 reg. reconoce a la Corte el poder de fallar, aunque las partes hayan solucionado el caso de manera extrajudicial. Esta disposición encuentra correspondencia en muchos sistemas nacionales de justicia constitucional con acceso incidental, mientras que normalmente no existe en los juicios de amparo o constitutional complaint. La razón es que el primer modelo defiende el valor de supremacía de la Constitución en abstracto; el segundo, en cambio, está interesado sólo en garantizar justicia en el caso concreto, y por eso no tendría sentido seguir adelante con un proceso, cuando las partes ya han encontrado una solución aceptada por ambas. En el sistema interamericano podemos acercar dos interpretaciones del art. 54 reg. De un lado, puede entenderse como una norma de salvaguardia de la parte débil, respecto a soluciones amistosas que sólo formalmente o simuladamente tutelan a la parte o restauran su derecho. De otro lado, la norma atribuye a la Corte un rol que va más allá de la garantía de los derechos en casos concretos, y que se orienta a proponer la CIDH como una "constitución universal", cuya supremacía debe ser defendida con efectos generales, según la misma lógica del control nomocrático de constitucionalidad. Esta situación es difusa en los casos de desaparición forzada, donde el reconocimiento de responsabilidad por parte del Estado no es suficiente, y hay, en cambio, que luchar por un objetivo más grande de restablecimiento de la verdad histórica: «La Corte Interamericana está llamada a establecer la verdad, una verdad material e histórica» (voto concurrente del juez Sergio García Ramírez, \17, caso Myrna Mack Chang, 2003).

La interpretación amplia del alcance de la CIDH está reforzada por la previsión de la función consultiva de la Corte (art. $64 \mathrm{CIDH}$, artt. $70 \mathrm{ss}$. Reg.), que puede ser activada tanto para obtener una interpretación autentica del tratado, como para pedir un juicio abstracto de convencionalidad entre una ley nacional y la CIDH, bajo recurso directo del Estado miembro (art. 64, c. 2 CIDH y art. 72 Reg.).

Como es bien sabido, la doctrina del control difuso de convencionalidad ha sido desarrollada tramite la jurisprudencia de la Corte, que, poco a poco, ha construido el sistema (Quinche Ramírez' 2010; Ferrer Mac-Gregor, s.f.'Hitters, 2009).

Con la sentencia Almonacid Arellano y otros vs. Chile, de $2006^{23}$, la Corte IDH ha impuesto a los jueces de los países miembros de la convención el ejercicio del control de convencionalidad difuso. Los fundamentos normativos utilizados por la Corte son los arts. 1 y $2 \mathrm{CIDH}^{24}$, que imponen a las partes de respetar los derechos y libertades reconocidos por el Pacto, garantizar el libre ejercicio de los derechos sin discriminación, y asumir las actas legislativas o de otra naturaleza necesarias para dar efectividad a los derechos; el art. 29, que impone de interpretar los derechos de la manera más amplia posible; el art. 69, que obliga los Estados a cumplir con las sentencias en los casos donde son partes en el juicio. Esto implica una obligación de adecuación normativa del ordenamiento nacional a la CIDH, pero la Corte ha establecido también que, en el caso en que el legislador no cumpla, y el juez se encuentre en deber de aplicar una norma ilegítima «el Poder Judicial debe ejercer una especie

\footnotetext{
${ }^{23}$ La idea ya había sido esbozada por algunos votos particulares del juez Sergio García Ramírez, a partir del caso Myrna Mack Chang de 2003, donde el juez utiliza por primera vez la expresión "control de convencionalidad", y del juez Antônio Augusto Cançado Trindade, a partir del caso La Última Tentación de Cristo (Olmedo Bustos y otros) vs. Chile, de 2001, donde afirma, al punto 9, que «las normas sustantivas - atinentes a los derechos protegidos - de un tratado de derechos humanos son directamente aplicables en el derecho interno de los Estados Partes en dicho tratado».

${ }^{24}$ «Artículo 1. Obligación de Respetar los Derechos. 1. Los Estados Partes en esta Convención se comprometen a respetar los derechos y libertades reconocidos en ella y a garantizar su libre y pleno ejercicio a toda persona que esté sujeta a su jurisdicción $[\ldots] \gg$.
} 
de "control de convencionalidad" entre las normas jurídicas internas que aplican en los casos concretos y la Convención Americana sobre Derechos Humanos» ${ }^{25}$. Sólo unos meses después, el principio viene reafirmado en el caso Trabajadores Cesados del Congreso (Aguado Alfaro y otros) vs. Perú, de 24 de noviembre 2006, donde la Corte fundamenta el control de convencionalidad sobre la obligación de respetar los compromisos asumidos con la firma del tratado, bajo las normas generales de derecho internacional ${ }^{26}$. En la misma sentencia se afirma el deber de ejercer el control ex officio.

En Almonacid y en Radilla Pacheco vs. Estados Unidos Mexicanos, de 2009, la Corte IDH especifica que el control debe ser ejercido considerando también su jurisprudencia (Gozaíni, 2008: 83; Nogueira Alcalá, 2013): «En esta tarea, el Poder Judicial debe tener en cuenta no solamente el tratado, sino también la interpretación que del mismo ha hecho la Corte Interamericana, intérprete última de la Convención Americana».

En el caso Cabrera García y Montiel Flores vs. México, de 26 noviembre 2010, en particular en el voto razonado del juez Ferrer Mac-Gregor, muchos aspectos de la doctrina del control de convencionalidad son aclarados y sistematizados, in primis la idea que lo deben ejercer «Los jueces y órganos vinculados a la administración de justicia en todos los niveles» (Ferrer Mac-Gregor, 2011b).

En el caso Gelman vs. Uruguay, de 2011, la Corte amplía ulteriormente los sujetos obligados, afirmando que todos los órganos, incluso los no jurisdiccionales, están obligados al control de convencionalidad ${ }^{27}$.

Finalmente, la Corte IDH llega hasta imponer a los Estados reformas constitucionales ${ }^{28}$, que ella considera necesarias para compatibilizar el ordenamiento interno con el Pacto de San José, presuponiendo el derecho internacional de los derechos humanos parte del bloque de normas y principios de nivel supra-constitucional, que limitan también el poder de revisión constitucional (Rey Cantor, Rey Anaya, 2014: Jinesta L., 2012: 238 ${ }^{29}$.

El sistema IDH no se propone sólo como "sistema internacional subsidiario de tutela de los derechos humanos". Esto implicaría la intervención de la Corte sólo bajo recurso de las partes, como en el caso del amparo, y un Derecho procesal convencional coherente con un juicio de partes. En cambio, es un sistema que garantiza la aplicación preferente de la CIDH, tanto en concreto

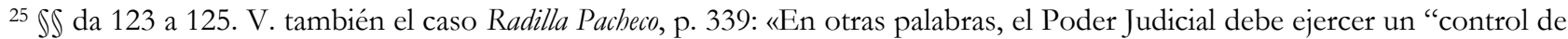
convencionalidad" ex officio entre las normas internas y la Convención Americana, evidentemente en el marco de sus respectivas competencias y de las regulaciones procesales correspondientes. En esta tarea, el Poder Judicial debe tener en cuenta no solamente el tratado, sino también la interpretación que del mismo ha hecho la Corte Interamericana, intérprete última de la Convención Americana».

26 «128. Cuando un Estado ha ratificado un tratado internacional como la Convención Americana, sus jueces también están sometidos a ella, lo que les obliga a velar porque el efecto útil de la Convención no se vea mermado o anulado por la aplicación de leyes contrarias a sus disposiciones, objeto y fin. En otras palabras, los órganos del Poder Judicial deben ejercer no sólo un control de constitucionalidad, sino también "de convencionalidad" ex officio entre las normas internas y la Convención Americana, evidentemente en el marco de sus respectivas competencias y de las regulaciones procesales correspondientes».

${ }^{27}$ Caso Gelman, \239 «[...] un "control de convencionalidad” (supra párr. 193), que es función y tarea de cualquier autoridad pública y no sólo del Poder Judicial». Sagüés, 2017: 56 ss.

${ }^{28}$ Ya desde la opinión consultiva OC-4/84, de 11 enero 1984, la Corte IDH afirma que las normas constitucionales deben ser interpretadas según Convención. El caso más noto es La Última Tentación de Cristo (Olmedo Bustos y otros) vs. Chile, de 2001, donde, al punto 4 del dispositivo, la Corte «decide que el Estado debe modificar su ordenamiento jurídico interno, en un plazo razonable, con el fin de suprimir la censura». En el caso, se trataba de una reforma de la Constitución que el Gobierno ya había propuesto, pero que durante el juicio todavía no se había aprobado.

${ }^{29}$ Punto 247 del caso Radilla Pacheco «La obligación estatal de adecuar la legislación interna a las disposiciones convencionales comprende el texto constitucional y todas las disposiciones jurídicas de carácter secundario o reglamentario». Cfr. Jinesta L., 2012: 16 s.: «En nuestro criterio, el "poder reformador", en cuanto poder constituido, tiene como límite infranqueable el "parámetro de convencionalidad", por lo que el órgano encargado del control de constitucionalidad bien podría ejercer el control de convencionalidad sobre las reformas que emita al texto constitucional, sobre todo, teniendo en cuenta uno de los principios básicos de los derechos humanos que es el de progresividad».
}

\begin{tabular}{llll}
\hline REVISTA DERECHO DE LAS MINORIAS & VOLUMEN 3 & 2020 & Page 33
\end{tabular} 
como en abstracto, frente a las fuentes internas de los ordenamientos de los Estados miembros, incluso la constitución misma (Jinesta, 2012: 3) ${ }^{30}$. La norma de adecuación (art. 2), la previsión del amicus curiae, el procedimiento consultivo, la autonomía del proceso ad quem respecto al proceso a quo, la eficacia erga omnes de la jurisprudencia de la Corte, incluso por los Estados no partes en el juicio $^{31}$, la constante afirmación que los jueces nacionales, en el ejercicio del control de convencionalidad son «jueces interamericanos», el poder de revisión del cumplimiento de las sentencias, son todos argumentos que soportan la interpretación propuesta.

Otra cuestión es si el intento de la Corte se está realizando en concreto. La lenta transformación del sistema interamericano de instrumento de tutela subsidiaria de los derechos hacia un verdadero sistema de "justicia convencional transnacional" ha encontrado críticas y oposición en su camino, debido a la ausencia de una común voluntad política entre todos los países de la OEA en aceptar las limitaciones de soberanía que tal visión implica, en particular frente a la idea de constitución como ley suprema (Gozaíni, 2008: 84). Un "conflicto entre Cortes" ya ha acontecido en varios países: en Uruguay, con el caso Gelman, donde la Corte Suprema se ha enfrentado contra el orden de renunciar a su poder de control de la constitucionalidad de las leyes, considerando la abrogación total de la ley de caducidad lesiva de los derechos constitucionales en materia penal; en Argentina, con el caso Fontevecchia, de 14 de febrero de 2017, donde la Corte Suprema se ha declarado vinculada sólo a las sentencias de la Corte IDH en las cuales el Estado argentino es parte (Ruiz-Morales, 2017: 144).

Del análisis del Report 2018 sobre la actividad de la Corte y de los datos publicados en la base de datos en el sitio oficial se aprende que de los 282 casos llegados a la Corte a partir de su institución hasta el 2018, bien 197 están todavía bajo juicio de revisión de ejecución (además de 32 casos pendientes de juicio y 14 a los cuales se ha aplicado el art. $65 \mathrm{CIDH}$ ). Esto significa que, si el incumplimiento total representa sólo el 5\% del total, el parcial llega hasta el 70\%. En particular, los Estados cumplen las obligaciones de indemnización moral y material de las víctimas, como la publicación de la sentencia de la Corte o el pago de la reparación, pero no cumplen las garantías de no repetición, es decir aquellos medios de reparación que no están dirigidos sólo a las víctimas en concreto, sino que benefician la colectividad en su conjunto, en cuanto requieren cambios estructurales, normativos o institucionales. A menudo consisten en: asunción de responsabilidad pública del Estado frente a la violación o al incumplimiento; implementación de reformas

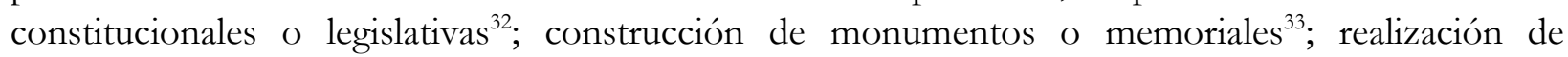

\footnotetext{
30 «El control de convencionalidad implica la necesidad de despojarse de una serie importante de lastres históricodogmáticos muy arraigados en la ciencia jurídica, derribar una serie de mitos (v. gr. la supremacía exclusiva de la Constitución) y, en definitiva, un nuevo paradigma del Derecho Público de los países del sistema interamericano»).

${ }^{31}$ Cfr. S 51, voto razonado del juez Eduardo Ferrer Mac-Gregor, caso Cabrera García y Montiel Flores vs. México, de 26 noviembre 2010.

32 «2. Regular, a la brevedad, los aspectos que considere necesarios para la implementación de la FIV, teniendo en cuenta los principios establecidos en la presente Sentencia, y debe establecer sistemas de inspección y control de calidad de las instituciones o profesionales calificados que desarrollen este tipo de técnica de reproducción asistida. El Estado deberá informar anualmente sobre la puesta en vigencia gradual de estos sistemas, de conformidad con el párrafo 337 de la presente Sentencia.

3. Caso Artavia Murillo y otros ("Fecundación In Vitro") vs. Costa Rica: «Incluir la disponibilidad de la FIV dentro de sus programas y tratamientos de infertilidad en su atención de salud, de conformidad con el deber de garantía respecto al principio de no discriminación. El Estado deberá informar cada seis meses sobre las medidas adoptadas para poner gradualmente estos servicios a disposición de quienes lo requieran y de los planes diseñados para este efecto, de conformidad con el párrafo 338 de la presente Sentencia.»

${ }^{33}$ Caso "Masacre de Mapiripán" vs. Colombia: «5. Construir, en el plazo de un año, contado a partir de la notificación de esta Sentencia, un monumento apropiado y digno para recordar los hechos de la masacre de Mapiripán, en los términos de los párrafos 315 y 326 de esta Sentencia». O en el caso Masacre de Pueblo Bello vs. Colombia: «7. Construir, en el plazo de un año, 
investigaciones penales y/o búsquedas de restos de personas desaparecidas; restitución de tierras a las comunidades indígenas ${ }^{34}$; consultas previas de las comunidades autóctonas ${ }^{35}$. Entonces, a parte de la euforia que -normalmente- la doctrina manifiesta hacia el sistema IDH, los datos demuestran que el sistema funciona bastante bien como instrumento subsidiario de tutela individual, mientras que un verdadero modelo de integración constitucional (más según el modelo UE que bajo el sistema EDU) está lejos de cumplirse. Los Estados siguen siendo reacios a seguir las directivas de política del Derecho dictadas por la Corte, que utiliza buena parte de sus recursos humanos y materiales en la supervisión de cumplimiento de sentencias.

A veces los Estados justifican su oposición con la falta de legitimación democrática de la Corte. Es un argumento evidentemente relacionado con la defensa de la soberanía nacional de los Estados, en elegir modos, tiempos e instrumentos para cumplir con las obligaciones derivadas del tratado. Otra vez, la distinta naturaleza de los dos sistemas de garantía no permite buscar una síntesis argumentativa en este ámbito. La "justicia convencional transnacional" se fundamenta en la aceptación a priori de la razonabilidad universal del concepto de derechos humanos. En cambio, la justicia constitucional en garantías de las minorías frente a la mayoría gubernamental contingente, que intenta violar los valores supremos sobre los cuales se fundó el consentimiento constituyente del pueblo.

La relación entre dogmática de los derechos y dogmática de la soberanía debería ser más fluida (Gargarella, 2015): cuando la situación política interna evidencia fuertes lagunas en el funcionamiento democrático de las instituciones, el sistema de "justicia convencional transnacional" debería entrar en función como generador de emergencia; cuando, en cambio, el debate democrático interno es capaz de garantizar de manera apropiada las minorías y los órganos de garantías pueden tutelar los casos particulares de violación de derechos, los sistemas internacionales deberían dar el paso a los instrumentos que gozan de manera directa o indirecta de legitimación popular. En este momento, la dinámica entre sistemas parece seguir la primera dirección, aún en Europa ${ }^{36}$.

\section{IV.2 El sistema EDU frente a los ordenamientos nacionales}

La Convención europea de los derechos humanos, firmada en Roma en 1950, entró en vigor en 1953. El sistema de garantías se fundamentaba al principio en dos órganos (art. 19): la Corte (actualmente existente) y la Comisión (abolida en 1998 con el protocolo 11), que desarrollaba el primer filtro al respecto de los recursos de las personas pro violaciones de la CEDU,en cuanto único órgano, además de los Estados, legitimados a llevar casos a la Corte (art. 44).

El objetivo del tratado es de garantizar el cumplimiento efectivo de los derechos humanos, ya establecido en la declaración ONU. Es un sistema de garantías subsidiario y condicionado:

\footnotetext{
contado a partir de la notificación de esta Sentencia, un monumento apropiado y digno para recordar los hechos de la masacre de Pueblo Bello, en los términos de los párrafos 278 y 286 de esta Sentencia».

${ }^{34}$ Caso Comunidades Afrodescendientes desplazadas de la Cuenca del Rio Cacarica (Operación Génesis) vs. Colombia: «4. Restituir el efectivo uso, goce y posesión de los territorios reconocidos en la normativa interna a las comunidades afrodescendientes agrupadas en el Consejo Comunitario de las Comunidades de la Cuenca del río Cacarica, de conformidad con lo establecido en el párrafo 459 de esta Sentencia».

35 Pueblo Indígena Kichwa de Sarayaku vs. Ecuador: «Consultar al Pueblo Sarayaku de forma previa, adecuada, efectiva y de plena conformidad con los estándares internacionales aplicables a la materia, en el eventual caso que se pretenda realizar alguna actividad o proyecto de extracción de recursos naturales en su territorio, o plan de inversión o desarrollo de cualquier otra índole que implique potenciales afectaciones a su territorio, en los términos de los párrafos 299 y 300 de esta Sentencia».

${ }^{36}$ Sajó, Giuliano, 2017: 532: «However, the fact of the matter is that the ECtHR is, against the Preamble of the Convention, gradually backing down from the maintenance and the further realization of human rights, replacing supranational adjudication with national sovereign will. Even more, in doing so it has increased uncertainty. Such uncertainty can undermine the entire supra-national project of human rights».
}

\begin{tabular}{llll}
\hline REVISTA DERECHO DE LAS MINORIAS & VOLUMEN 3 & 2020 & Page 35
\end{tabular} 
requisito de admisibilidad es el agotamiento previo de los recursos internos; además, la acción debe ser promovida dentro de 6 meses $^{37}$ de la fecha de publicación de la sentencia definitiva sobre el caso.

En 1963 se suscribe el Protocolo n. ${ }^{\circ}$ 2, entrando en vigor en 1970 y, luego, substituido por el Protocolo n. ${ }^{\circ} 11$ que añade la competencia consultiva de la Corte $^{38}$, la que, sin embargo, tiene un ámbito de aplicación muy estrecho, en cuanto no puede interesarse por la interpretación abstracta de un derecho establecido por la convención ${ }^{39}$. En el explanatory Report esta decisión se justifica por la voluntad de no mezclar competencias consultiva y contenciosa ex arts. 33 e 34.

A partir de 1998, con el protocolo $n .^{\circ} 11$, la Corte se vuelve órgano permanente de tiempo completo, y puede ser objeto de acceso directo por los individuos. La última modificación interesante es de 2010, cuando se aprueba el Protocolo n. ${ }^{\circ} 14$, con la finalidad de introducir instrumentos para garantizar la sustentabilidad del trabajo de la Corte: el mandato de los jueces es extendido a 9 años y se introduce como requisito de admisibilidad de los recursos la prueba de un «significant disadvantage» para el recurrente.

Están, a la fecha abiertos, a la ratificación dos protocolos, el n. ${ }^{\circ} 15 \mathrm{y}$ el n. ${ }^{\circ} 16$, que representan interesantes desarrollos del sistema europeo de tutela de los derechos.

De un lado, con el Protocolo n. ${ }^{\circ}$ 15, los Estados se oponen a la transformación del sistema en sentido "constitucional", reivindicando su naturaleza integrativa de los sistemas nacionales, en lo atinente a la inclusión en el preámbulo de la CEDU de la referencia al principio de subsidiariedad y al margen de apreciación. Además, se reduce a 4 meses el plazo para proponer recursos. De otro lado, con el Protocolo n. ${ }^{\circ} 16$, se introduce la posibilidad, por parte de las más altas jurisdicciones nacionales, de pedir a la Corte una opinión consultiva acerca de la interpretación de los derechos contenidos en la CEDU, fortaleciendo el diálogo entre cortes nacionales y la corte de Estrasburgo. En el informe explicativo, se puede leer que el grupo de expertos, instituidos en 2005 para reflexionar sobre la eficacia a largo plazo del sistema europeo de garantía de la CEDU, había -al principio- indicado entre las finalidades de la función consultiva la de «fortalecer el rol "constitucional" de la Corte». Sin embargo, ya en la conferencia de Smirne de 2011, el alcance de este objetivo había sido restringido y cambiado por «ayudar los Estados a evitar futuras violaciones». El mecanismo es direccionado a mejorar la eficiencia del sistema y, en el fondo, a evitar que lleguen a la Corte casos que se hubieran podido resolver directamente por el juez del caso, bajo una correcta interpretación de la CEDU. Esto significa que el objetivo del Protocolo n. ${ }^{\circ}$ 16, en línea con lo del protocolo n. ${ }^{\circ}$ 15, debe ser interpretado en el sentido de lograr una mejor eficacia del sistema, disminuyendo el número de casos que llegan a la Corte ${ }^{40}$. Aun en la óptica del dialogo, los dos niveles de tutela, nacional y supra-nacional, quedan diferenciados y separados, tanto que la opinión consultiva de la Corte no es vinculante, de manera a respetar la completa autonomía de juicio de los jueces nacionales. La Corte se queda como intérprete supremo del Tratado, pero no del Derecho interno, como -en cambio- se produce con el mecanismo consultivo previsto por el sistema

\footnotetext{
37 , Protocolo N. ${ }^{\circ} 15$.

38 Art. 47 «... give advisory opinions on legal questions concerning the interpretation of the Convention and the protocols thereto».

39 Se lee, de hecho, en el Segundo párrafo: «Such opinions shall not deal with any question relating to the content or scope of the rights or freedoms defined in Section I of the Convention and the protocols thereto, or with any other question which the Court or the Committee of Ministers might have to consider in consequence of any such proceedings as could be instituted in accordance with the Convention».

${ }^{40}$ Reflection paper on the proposal to extend the court's advisory jurisdiction, https://www.echr.coe.int/Documents/2013 Courts advisory_jurisdiction ENG.pdf: «the longer term objective would clearly be to ensure that more cases were dealt with satisfactorily at national level» (p. 1) e «should, in the long run, help reduce the Court's overall workload» (p. 4).
} 
interamericano. La Corte ya se había pronunciado sobre el punto, rechazando la idea que el mecanismo pudiese ser entendido como una especie de recurso directo de convencionalidad ${ }^{41}$. El Protocolo n. 16 ha entrado en vigor el 1 de agosto de 2018, sólo por los Estados que lo han ratificado, así que este ciclo se puede considerar una especie de fase experimental ${ }^{42}$.

La ampliación hacia el Este del ámbito de aplicación de la CEDU, sin embargo, ha producido un cabio en la jurisprudencia de la Corte europea en materia de relación entre la CEDU y el Derecho nacional. La Corte se ha vuelto más "agresiva", para garantizar estándares de tutela de los derechos más elevados, en países con un evidente retraso en su concreto reconocimiento. Hoy en día, se puede detectar una tendencia hacia la transformación del sistema europeo de un modelo de "justicia individual" hacia uno de "justicia constitucional" (Pollicino, Sciarabba' 2011: 23; Pollicino, 2010: 129). De hecho, bajo el tratado, la Corte EDU juzga sobre violaciones de la CEDU caso por caso, tramite sentencia con eficacia inter partes, ex art. 46, c. 1, que no constituyen precedente vinculante. En cambio, la jurisprudencia de la Corte está marchando en dirección opuesta, por medio de las sentencias pilotos y de la eficacia de res interpretata de sus fallos, con el consiguiente ampliamente del efecto indirecto de las sentencias hacia los Estados que no son partes en el juicio, es decir con eficacia erga omnes. Las sentencias-pilotos haN sido disciplinadas en el art. 61 Reg. en 2011. Es un procedimiento que permite a la Corte resolver un caso concreto y, al mismo tiempo, dictar indicaciones pro futuro, respecto a la misma situación de hecho, que parece emblemática de un problema estructural o sistémico de adecuación del ordenamiento interno a la CEDU, entonces de una situación lesiva potencialmente repetible. El mismo efecto se podría producir con las opiniones consultivas (Pérez Sola, 2017: 1310; Cárdenas Velásquez, 2018: 53).

\section{IV.3 La aplicación directa del derecho de la UE por parte de los jueces de los países miembros}

Una forma de "control de convencionalidad" se realiza por parte de los jueces de los países miembros de la UE respecto a los actos normativos de la UE directamente vinculantes. La primacía del Derecho de la UE sobre el Derecho interno se ha afirmado por vía jurisprudencial durante el proceso de integración europeo, iniciado con los tratados que instituyeron la Comunidad económica del carbón y del acero, en 1951, de la Comunidad económica europea (CEE) y de la Comunidad europea para la energía atómica (Euratom), en 1958. Actualmente, las últimas revisiones del proceso remontan al tratado de Lisboa, entrado en vigor en 2009. La declaración n. ${ }^{\circ} 17$, anexa a los tratados, reafirma el principio de primacía, citando expresamente la jurisprudencia constante de la CGUE, inaugurada con el caso Costa c. Enel de 1964. El análisis de los argumentos utilizados durante la "guerra entre las cortes" que se produjo en aquellos años, sobre todo por parte de las Corte constitucionales italiana y alemana, confirma que la desaplicación del Derecho interno incompatible con el Derecho de la UE por parte de los jueces ordinarios no es una solución que deriva de la aplicación al sistema UE de las teorías sobre las fuentes elaboradas por el Derecho constitucional, sino el fruto de una construcción jurídica novedosa. En Italia, la Corte constitucional, en 1964 y en 1973, con la sent. n. 183, incorpora el principio de primacía del Derecho comunitario, pero al mismo tiempo, defiende los presupuestos del sistema de justicia constitucional, cuando afirma que la ley entrada en vigor después del Derecho de la UE necesita ser sometida al control de constitucionalidad. Sólo después del caso Simmenthal, la Corte constitucional acepta los argumentos de la CGUE, renunciando a esquemas interpretativos y marcos jurídicos constitucionales

\footnotetext{
$41 \ll[\ldots]$ there should not be an abstract review of legislation» (p. 6).

${ }^{42}$ La primera opinión consultiva a la Corte EDU ha sido pedida por la Cour de Cassation francesa, Assemblée plénière, con el arrêt $\mathrm{n}^{\circ} 638$ du 5 octobre 2018 (10-19.053), sobre la compatibilidad con la CEDU de una norma que prohíbe a la madre "d'intention" de inscribirse en el registro de estado civil como madre "legal" de un niño nacido al extranjero con subrogación de maternidad.
} 
«verosimilmente indisponibili», y aceptando el control difuso de "comunitariedad" (Ruggeri, 2019b: 316), pero contribuyendo a la elaboración de la doctrina de los contra-límites.

La coherencia de la perspectiva originaria de las Cortes nacionales, aún considerando la evolución del proceso de integración, está confirmada por la más reciente jurisprudencia de muchas Cortes constitucionales, que han aplicado la teoría de los contra-límites y se han vuelto a reivindicar su competencia en controlar la compatibilidad entre el Derecho interno y el Derecho de la UE, cuando el parámetro está constituido por principios fundamentales del ordenamiento o derechos establecidos por la CEDU.

En el Lissabon Urteil, el Tribunal constitucional federal alemán afirma -varias veces- que los Estados miembros son los reales señores de los tratados, rechazando su naturaleza "constitucional", y ha reiterado su competencia para controlar que el Derecho europeo respete la identidad nacional y los principios fundamentales del Estado alemán, ya afirmada en el caso Solange en 1974: «The obligation under European law to respect the constituent power of the Member States as the masters of the Treaties corresponds to the non-transferable identity of the constitution (Article 79.3 of the Basic Law), which is not open to integration in this respect. Within the boundaries of its competences, the Federal Constitutional Court must review, where necessary, whether these principles are adhered to» ( $(235)$ (Mezzetti, 2019: 172 ss.).

En el caso Taricco (CGUE, C-105/14, 8 de septiembre de 2015), por primera vez las cortes italianas han promovido una cuestión de legitimidad constitucional frente a la interpretación conforme del Derecho interno frente al derecho de la UE, impuesta por la CGUE, que invitaba los jueces a desaplicar normas sobre la prescripción penal prejudiciales por los intereses financieros de la UE en materia de VAT. La Corte constitucional italiana, después de haber promovido una cuestión prejudicial comunitaria, ha reafirmado, en la sent. N. ${ }^{\circ} 115 / 2018$, que «spetta in via esclusiva il compito di accertare se il diritto dell'Unione è in contrasto con i principi supremi dell'ordine costituzionale e in particolare con i diritti inalienabili della persona».

Por lo restante, la doctrina de los contra-límites ha sido "comunitarizada" con el Tratado de Lisboa. El art. 4, c. 2 TUE ahora declara expresamente que la UE respeta la identidad nacional de los Estados miembros, así que, de disposición de salvaguardia de la soberanía constitucional de los Estados, la doctrina de los contra-límites se ha transformado en parámetro de legitimidad del derecho de la UE,aplicable por la CGUE.

Finalmente, el art. 6 TUE reconoce los derechos establecidos por la CEDU como principios generales del derecho de la UE. Esta nueva disposición ha producido un debate en doctrina sobre la posibilidad que, por medio del art. 6, se pueda extender el "control de convencionalidad" comunitario a los casos de violación del Derecho EDU. Sin embargo, la misma CGUE se ha pronunciado sobre el asunto, defendiendo la tesis que la relación entre Derecho interno y Derecho de la UE no se extiende automáticamente al sistema EDU. La Corte ha afirmado que el TUE «non disciplina il rapporto tra la CEDU e gli ordinamenti giuridici degli Stati membri e nemmeno determina le conseguenze che un giudice nazionale deve trarre nell'ipotesi di conflitto tra $\mathrm{i}$ diritti garantiti da tale convenzione ed una norma di diritto nazionale», por lo que «il rinvio operato dall'articolo 6, paragrafo 3, TUE alla CEDU non impone al giudice nazionale, in caso di conflitto tra una norma di diritto nazionale e detta convenzione, di applicare direttamente le disposizioni di quest'ultima, disapplicando la norma di diritto nazionale in contrasto con essa» ( $\mathbb{S} 63$, Grande Sezione, 24 aprile 2012, caso Servet Kamberaj, causa C-517/10).

\section{La “justicia convencional transnacional” como autónomo sistema degarantía de los derechos humanos}

El objetivo de este articulo ha sido reflexionar sobre la naturaleza de las distintas formas de control de convencionalidad elaboradas en algunos sistemas jurídicos supranacionales, para entender si es metodológicamente correcto considerarlas, como parece hacer la doctrina con gran aplomo, especies del genus de la "justicia constitucional", en base a las similitudes existentes entre las formas 
procesales utilizadas para garantizar la supremacía del derecho de origen convencional sobre el derecho interno.

A partir de la segunda mitad del siglo pasado, varios tribunales supranacionales han sido creados, como órganos de implementación, tanto de tratados regionales sobre derechos humanos, como de sistemas internacionales de integración económica. En muchos casos, un sistema de acceso directo e individual a estos tribunales ha sido previsto, frente a conductas activas u omisivas de los Estados, en violación de normas convencionales. Sin embargo, sólo en algunos sistemas (UE y los sistemas EDU y IDH), el nivel de las relaciones internacionales y el de las relaciones jurídicas entre individuos dentro de los ordenamientos estatales se han mezclado, mediante la afirmación de principios como la primacía y el efecto directo y los instrumentos procesales de la prejudicialidad y del control de convencionalidad. Se ha creado una superposición, hasta la fecha, inexistente en la ciencia jurídica, que siempre había trazado una frontera rígida entre las disciplinas del Derecho constitucional y del Derecho internacional, en virtud de los distintos sujetos de derecho y de los límites de aplicación de las normas producidas en cada esfera jurídica

Mi posición, compartida de hecho también por la jurisprudencia de algunas Cortes constitucionales (supra, \IV), es que, a pesar de las similitudes entre formas, control de convencionalidad y control de constitucionalidad tienen dos fuentes de legitimación distintas, aún si el parámetro que aplican es, a menudo, intercambiable. Esto implica que, en la mayoría de los casos concretos, la solución a la cual llegan es idéntica (sobre todo en ámbito de garantía de los derechos), a causa de la incorporación del Derecho de origen convencional en los ordenamientos nacionales. La inclusión del Derecho internacional en el bloque de constitucionalidad permite absorber el control de convencionalidad dentro del sistema de justicia constitucional vigente en cada ordenamiento, que es lo que pasa en muchos países del sistema EDU. La imposición jurisprudencial del instrumento de la desaplicación directa del Derecho interno incompatible, en cambio, crea una ruptura de los principios constitucionales que regulan las fuentes y la relación entre poderes, basados en la teoría del poder constituyente como fundamento de la supremacía de la Constitución.

Apoyar esta conclusión teórica no significa rechazar de manera anacrónica los logros obtenidos ni en ámbito de tutela de los derechos humanos tramite los sistemas regionales de garantías ni en ámbito de los procesos de integración internacional. Mi tesis implica reconocer que es necesario un enfoque metodológico distinto para el estudio de estos fenómenos, como de hecho se ha producido en la doctrina europea frente al estudio del sistema UE. Hay que aceptar que la “justicia convencional transnacional” es un instrumento de garantía que, aún dialogando con la justicia constitucional nacional, no se puede explicar con los mismos presupuestos teóricos, y necesita de una elaboración doctrinal propia y de presupuestos jurídicos-filosóficos autónomos respecto a la ciencia del derecho constitucional. Como ya en América Latina ha pasado con el Derecho procesal constitucional, la imitación e hibridación de institutos y principios propios de ciencias ya existentes produce una nueva disciplina jurídica, en mi opinión rama del Derecho internacional. De todos modos, es indudable que permanezcan fuertes interacciones con la justicia constitucional, debido a que las dos disciplinas comparten el mismo objeto de tutela, es decir los derechos humanos. 
Bagni, S. (2017).Oltre i modelli e i sistemi di giustizia costituzionale e convenzionale: alcune riflessioni di método. Diritto pubblico comparato ed europeo, n. 4, 1067-1095.

Bazán, V. (2011). En torno al control de convencionalidad. En M. Maldonado Muñoz (ed.), Ruptura n. 54, Quito: Cevallos.

Canosa Usera, R. (2015).¿Es posible el control pleno de convencionalidad en España?. En M. Carbonell Sánchez, H. Fix Fierro, D. Valadés (coords), Estado constitucional, derechos humanos, justicia y vida universitaria. Estudios en homenaje a Jorge Carpizo. Derechos humanos, tomo V, vol. 1. México:Unam.

Cárdenas Velásquez, B.G. (2018).El control de las normas internas en la jurisprudencia del Tribunal Europeo y la Corte Interamericana de Derechos Humanos. Especial consideración de su aplicación en España y Nicaragua. Barcelona: Bosch.

Carducci, M. (2012). Argomento comparativo e presunzione di isomorfismi interordinamentali: spunti critici dalla prospettiva latinoamericana. En Aa.Vv., Studi in onore di Aldo Loiodice. Bari: Cacucci.

Chang, W-C., Yeh, J-R. (2012).Internalization of Constitutional Law. En M. Rosenfeld, A. Sajó (eds), The Oxford Handbook of Comparative Constitutional Law. Oxford: OUP.

de Figueiredo Caldas, R. (2013). O Controle de Constitucionalidade e o Controle de Convencionalidade no Brasil. Anuario de derecho constitucional latinoamericano, n. 13.

De Oliveira Mazzuoli, V. (2016). O controle jurisdicional da convencionalidade das leis, 4. ${ }^{\mathrm{a}}$ ed. revista, actualizada e ampliada. São Paulo: Editora Revista dos Tribunais Ltda.

Della Cananea, G. (2010). Is European Constitutionalism Really “Multilevel”?.ZaöRV, n. 70, 283-317 (on line https://www.zaoerv.de/70 2010/70 2010 2 a 283 318.pdf.)

Di Gregorio, A. (2004). Riforme costituzionali e integrazione europea: il caso dei nuovi membri dell'Est.Dir. Pubb. Comp. Eur., n. 4.

Drago, G. (2016). Contentieux constitutionnel français, 4ème éd. Paris: Puf.

Dulitzky, A.E. (2015). An Alternative Approach to the Conventionality Control Doctrine.109 AJIL Unbound 100. http://www.iconnectblog.com/2015/11/symposium-on-the-constitutionalization-of-international-law-in-latin-america/\#_ftnref6

Dutheillet De Lamothe, O. (2009).Visite au Tribunal Constitutionnel espagnol, Madrid, 2-4 de avril 2009, http://www.conseilconstitutionnel.fr/conseil-constitutionnel/francais/publications/contributions-et-discours/2009/controle-de-conventionnalite-etcontrole-de-constitutionnalite-en-france.147129.html

Favoreu, L., Mastor, W. (2016).Les cours constitutionnelles, $2^{\circ}$ éd. Paris: Dalloz.

Ferrer Mac-Gregor, E. (2015). Conventionality Control: The New Doctrine of the Inter-American Court of Human Rights. 109 AJIL Unbound 93. http://www.iconnectblog.com/2015/11/symposium-on-the-constitutionalization-of-international-law-in-latinamerica/\#_ftnref6

Ferrer Mac-Gregor, E. (s.f.).El control difuso de convencionalidad en el Estado constitucional, https://archivos.juridicas.unam.mx/www/bjv/libros/6/2873/9.pdf

Ferrer Mac-Gregor, E. (2011).Interpretación conforme y control difuso de convencionalidad. El nuevo paradigma para el juez mexicano. Estudios Constitucionales, n. 2, 531-622.

Ferrer Mac-Gregor, E. (2011b). Interpretación conforme y control difuso de convencionalidad. El nuevo paradigma para el juez mexicano. https://archivos.juridicas.unam.mx/www/bjv/libros/7/3033/14.pdf.

Ferrer Mac-Gregor, E. (2011c).Reflexiones sobre el control difuso de convencionalidad (A la luz del Caso Cabrera García y Montiel Flores vs. México). En M. Maldonado Muñoz (ed.), Ruptura n. 54, Quito. 363-411.

Fix-Zamudio, H. (1999). Breves reflexiones sobre el concepto y el contenido del derecho procesal constitucional. Anuario iberoamericano de justicia constitucional.

García Roca, J. (2010). El margen de apreciación nacional en la interpretación del Convenio Europeo de Derechos Humanos: soberanía e integración. Cizur Menor: Thomson Reuters.

Gargarella, R. (2015). La democracia frente a los crímenes masivos: una reflexión a la luz del caso Gelman. Revista Latinoamericana de Derecho Internacional, 1-15.

González-Trevijano Sánchez, P.J (2000).El Tribunal Constitucional. Elcano: Aranzadi.

Gozaíni, O.A. (2008). El impacto de la jurisprudencia del sistema interamericano en el derecho interno. En S. Albanese (coord.), El control de convencionalidad. Buenos Aires: Ediar. 
Hitters, J.C. (2009). Control de constitucionalidad y control de convencionalidad. Comparación (Criterios fijados por la

Corte Interamericana de Derechos Humanos). Estudios constitucionales, vol. 7, n. 2, 109-128, https://scielo.conicyt.cl/scielo.php?script=sci_arttext\&pid=S0718-52002009000200005\&lng=es\&nrm=iso.

Jimena Quesada, L. (2018). El control de convencionalidad y los derechos sociales: nuevos desafíos en España y en el ámbito comparado europeo (Francia, Italia y Portugal). Anuario iberoamericano de justicia constitucional, n. 22, 31 ss.

Jimena Quesada, L. (2013). Jurisdicción nacional y control de convencionalidad a propósito del diálogo judicial global y de la tutela multinivel de derecho. Cizur Menor: Aranzadi.

Jinesta L., E. (2012). Control de convencionalidad ejercido por los Tribunales y Salas Constitucionales. En E. Ferrer Mac-Gregor (coord.). El Control Difuso de Convencionalidad. Diálogo entre la Corte Interamericana de Derechos Humanos y los jueces nacionales. México: Fundap(versión on line).

Locke, J. (1823).Two Treatises of Government, A New Edition, Corrected, In Ten Volumes, Vol. V. London/Dublin. http://www.yorku.ca/comninel/courses/3025pdf/Locke.pdf.

Martinico, G., Pollicino, O. (2012). The Interaction between Europe's Legal Systems. Judicial Dialogue and the Creation of Supranational Laws, Cheltenham/Northampton: Elgar Pub.

Martins, L., Oliveira Moreira, T. (2011). Constitucionalidade e Convencionalidade de Atos do Poder Público: concorrência ou hierarquia? Um contributo em face da situação jurídico-constitucional brasileira. Anuario de derecho constitucional Latinoamericano, n. 11.

Mezzetti, L. (2019). Principi costituzionali e forma dell'Unione. En P. Costanzo, L. Mezzetti, A. Ruggeri. Lineamenti di diritto costiturionale dell'Unione europea. Turin: Giappichelli.

Nogueira Alcalá, H. (2013). Diálogo interjurisdiccional y control de convencionalidad entre los tribunales nacionales y la Corte Interamericana de Derechos Humanos en Chile. Anuario de derecho constitucional latinoamericano, n. 13.

Pérez Sola, N. (2017). El diálogo entre los tribunales: Tribunal Constitucional español y el Tribunal Europeo de Derechos Humanos. En S. Bagni, G.A. Figueroa Mejía, G. Pavani (coords).La ciencia del derecho constitucional comparado. Libro homenaje a Lucio Pegoraro, II. México: Tirant lo Blanch.

Pérez Tremps, P. (1992). Las garantías constitucionales y la jurisdicción internacional en la protección de los derechos fundamentales. Anuario de la Facultad de Derecho, n. 10, Universidad de Extremadura.

Pérez Tremps, P. (2016).Sistema de Justicia Constitucional, $2^{\circ}$ ed.Cizur Menor: Civitas-Thomson Reuters.

Pernice, I. (1999). Multilevel Constitutionalism and the Treaty of Amsterdam: European Constitution-Making Revisited?.Common Market Law Review, Issue 4, n. 39.

Pernice, I. (s.f.). Multilevel Constitutionalism in the European Union, http://www.whi-berlin.de/documents/whi-paper0502.pdf.

Pizzolo, C. (2008). La relación entre la Corte Suprema de Justicia y la Corte Interamericana de Derechos Humano a la luz del bloque de constitucionalidad federal. En S. Albanese (coord.), El control de convencionalidad, Buenos Aires:Ediar.

Pizzorusso, A. (2007). Giustizia costituzionale (diritto comparato). Enc. Dir.,Annali, I. Milán: Giuffrè.

Pollicino, O. (2010). Allargamento dell'Europa a est e rapporto tra Corti costituzionali e Corti europee. Verso una teoria generale dell'impatto interordinamentale del diritto souranažionale?. Milán: Giuffrè.

Pollicino, O., Sciarabba, V. (2011). La Corte di giustizia dell'Unione europea e la Corte europea dei diritti dell'uomo quali Corti costituzionali. En L. Mezzetti (cur.), Sistemi e modelli di giustiz̧ia costiturionale, tomo II. Padua: Cedam.

Quinche Ramírez, M.F. (2010). El control de convencionalidad. Un control judicial para el siglo XXI. En Aa.Vv., Realidades y tendencias del derecho en el siglo XXI - Derecho público. tomo VI. Temis/Pontificia Universidad Javeriana, 573-601.

Ragone, S. (2017). The Inter-American System of Human Rights. Essential Feature. En A. von Bogdandy et al. (eds).Transformative Constitutionalism in Latin America: the Emergence of a new Ius Commune. Oxford: OUP.

Reflection paper on the proposal to extend the court's advisory jurisdiction (2013). https://www.echr.coe.int/Documents/2013 Courts advisory jurisdiction ENG.pdf.

Rey Cantor, E. (2010).La Jurisdicción Constitucional y Control de Convencionalidad de las Leyes. En P.L. Manili (dir.).Tratado de Derecho Procesal Constitucional Argentino, Comparado y Transnacional, Buenos Aires: La Ley. 
Rey Cantor, E., Rey Anaya, A.M. (2014).Control de convencionalidad (test). En E. Ferrer Mac-Gregor, F. Martínez Ramírez, G.A. Figueroa Mejía (coords), Diccionario de Derecho Procesal Constitucional y Convencional. México: Poder Judicial de la Federación, Consejo de la Judicatura Federal, Unam-Instituto de Investigaciones Jurídicas.

Rolla, G. (cur.) (2010),Il sistema europeo di protezione dei diritti fondamentali e i rapporti tra le giurisdirioni. Milán: Giuffrè.

Ruggeri, A. (2019). Una Costituzione e un diritto costituzionale per l'Europa unita. En P. Costanzo, L. Mezzetti, A. Ruggeri, Lineamenti di diritto costituzionale dell'Unione europea, Turin: Giappichelli.

Ruggeri, A. (2019b). Le fonti eurounitarie e le fonti nazionali.En P. Costanzo, L. Mezzetti, A. Ruggeri, Lineamenti di diritto costituzionale dell'Unione europea, Turin: Giappichelli.

Ruggeri, A. (2007).La tutela "multilivello" dei diritti fondamentali, tra esperienze di normazione e teorie costituzionali. Politica del diritto, n. 3 .

Ruiz-Morales, M.L. (2017). El control de convencionalidad y los sistemas de protección de los derechos humanos americano y europeo. Su recepción en el caso argentino y español. Anuario Iberoamericano de Justicia Constitucional, 21.

Sagüés, N.P (s.f.). El "control de convencionalidad" en el sistema interamericano, y sus anticipos en el ámbito de los derechos económico-sociales. Concordancias y diferencias con el sistema europeo,http://www.pj.gov.py/ebook/monografias/extranjero/derechos-humanos/Néstor-Pedro-Sagués-El-Control-deConvencionalidad.pdf.

Sagüés, N.P. (2011).Control de constitucionalidad y control de convencionalidad: a propósito de la "constitución convencionalizada". Parlamento y Constitución, n. 14, 143-152.

Sagüés, N.P. (2017). Notas sobre el control ejecutivo de convencionalidad. En V. Bazán, E. Castro Rivera, S.J. Cuarezma Terán (dir.), Estado constitucional y convencional, Managua: INEIJ.

Sajó, A., Giuliano, S. (2017).Is the Decline of Globalization the End of Human Rights?.Annuario di diritto comparato, 520 s.

Salvino, T. (2017). L'apertura delle Costituzioni degli Stati membri dell'UE al diritto comunitario e a quello internazionale. Un confronto tra Est e Ovest d'Europa. Turin: Giappichelli.

Spadaro, A. (2006). Costituzione (dottrine generali). En S. Cassese (dir.), Diz̧ionario di diritto pubblico, vol. II. Milán: Giuffrè.

Tega, D. (2012). I diritti in crisi. Tra Corti nazionali e Corte europea di Strasburgo. Milán: Giuffrè.

Von Bogdandy, A. (2015).Ius Constitutionale Commune en América Latina: una mirada a un constitucionalismo transformador. Revista Derecho del Estado, n. 34, pp. 3-50.

Walker, N. (2009). Multilevel Constitutionalism: Looking Beyond the German Debate. LEQS Paper No. 08. http://www.lse.ac.uk/european-institute/Assets/Documents/LEQS-Discussion-Papers/LEQSPaper8Walker.pdf.

Zagrebelsky, G., Marcenò, V. (2012). Giustiz̨ia costiturionale, Bolonia: il Mulino. 